\title{
ВОЗМОЖНОСТИ ИСПОЛЬЗОВАНИЯ ЗАРУБЕЖНОГО ОПЫТА ДЛЯ РАЗВИТИЯ «КРАУДФАНДИНГА» В РОССИИ
}

\author{
(C) 2020 Гречкин Назар Васильевич \\ аспирант, кафедра «Мировой экономики» \\ Российская академия народного хозяйства и государственной службы при Президенте Российской \\ Федерации, Россия, Москва \\ E-mail: nazargrechkin@yandex.ru \\ (c) 2020 Абрамов Валерий Леонидович \\ доктор экономических наук, профессор, главный научный сотрудник Института исследований \\ международных экономических отношений \\ Финансовый университет при Правительстве Российской Федерации, Россия, Москва \\ E-mail:valabr@yandex.ru
}

В статье освещен зарубежный опыт применения и развития краудфандинговых платформ на основе обобщения имеющихся данных. Актуальность статьи состоит в том, что краудфандинг в России только начинает свое развитие в сопоставлении с ведущими зарубежными странами. В статье сформулированы теоретические и практические рекомендации по повышению уровня интереса и финансированию краудфандинга в России.

Ключевые слова: краудфандинг, краудфандинговые платформы, закон о краудфандинге, научнопрактические рекомендации.

В развитых странах мира краудфандинг уже зарекомендовал себя как инновационный высокотехнологичный финансовый инструмент аккумулирования средств с целью реализации проектов и поддержки стартапов. Несмотря на экономический климат, объемы, собранные в 1-м полугодии 2020 года в мире, продолжили увеличиваться на $34 \%$ по сравнению с 1-м полугодием 2019 года и достигли 320374570 евро [4]. Этот метод финансирования имеет ряд преимуществ, однако его применение на территории России несколько ограничено в связи с определенными технологическими, экономическими и социальными барьерами.

Часто под понятием краудфандинга понимают - механизм привлечения финансирования от широких масс с целью реализации проекта. Проекты могут быть культурные, социальные, коммерческие, политические, экологические, личные. В своем большинстве, финансирование опирается на небольшие взносы, осуществленные большой массой людей. При этом очень активно используется сеть Интернет, и отсутствуют стандартные финансовые посредники. Роль посредника играет краудфандинговая компания, которая осуществляет все необходимые организационно контрольные функции.

Ключевыми участниками системы крауд-

фандинга являются (рис. 1):

- авторы проекта или реципиенты - это люди, имеющие необходимость в определенном количестве финансовых ресурсов для реализации проекта, имеющего целью предоставление услуги, создание товара или реализацию какого-то события;

- работники краудфандинговой платформы или медиатора - то есть люди, отвечающие за функционирование такой краудфандинговой платформы;

- доноры проекта - лица, желающие поддержать определенный проект;

- государство - осуществляет регуляторную деятельность и облагает налогом доходы участников краудфандинговой деятельности.

Отметим некоторые из преимуществ краудфандинга, которые заключаются в следующем:

- владельцы имеют больший контроль над своим проектом (т.е. сроком погашения, схемами акций), чем в случае банковского кредита или венчурных капиталистов;

- более низкая стоимость финансирования; распространение риска на круг инвесторов;

- владельцы могут проводить рыночные тесты для своих продуктов или услуг во время кампаний и получить другие средства от финансовых учреждений в будущем. 


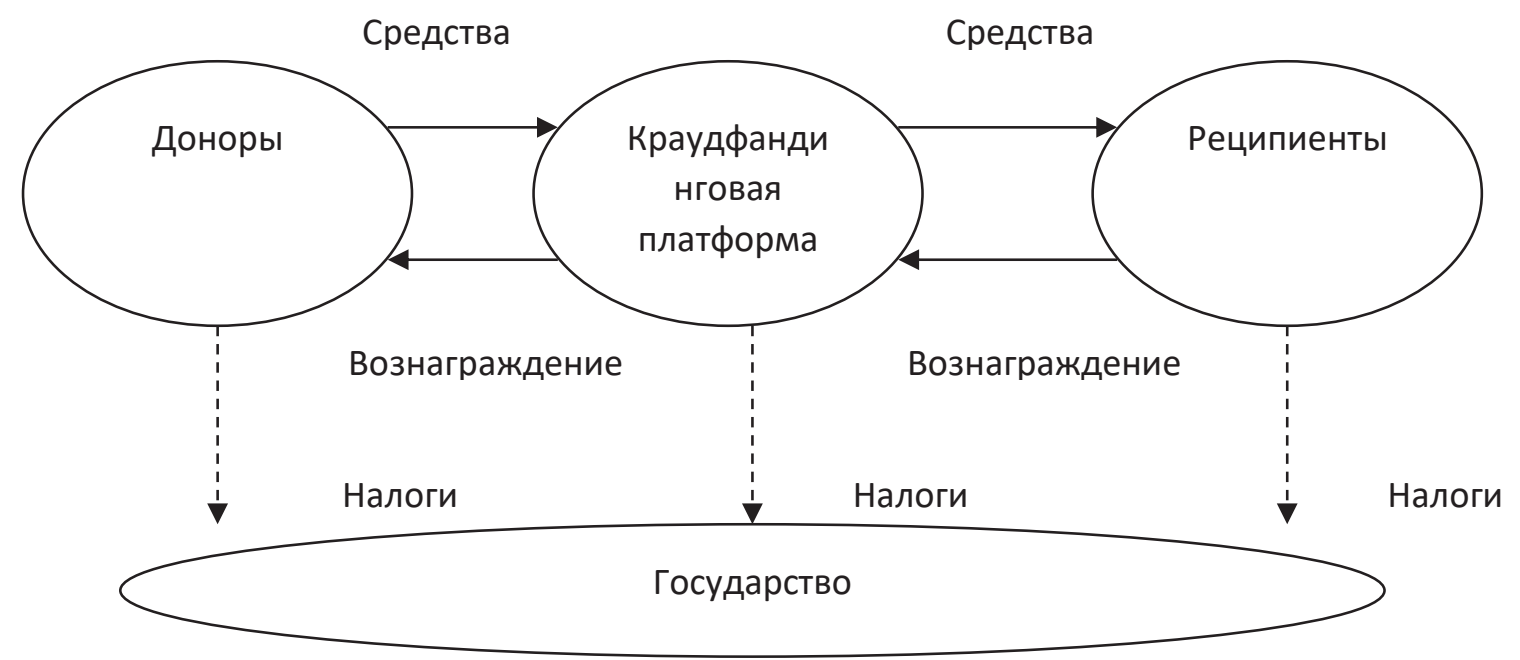

Рисунок 1. Участники процесса краудфандинга

Использование альтернативных инструментов финансирования, таких как краудфандинг, дает много преимуществ, но следует также учитывать риски и некоторые другие препятствия (недостаточная осведомленность и понимание альтернативных инструментов, финансовых учреждений и правительств), которые удерживают их в более низкий уровень, чем существующий потенциал.

Важным фактором являются сроки запуска проекта. Согласно открытым статистическим данным мы можем увидеть, что несколько дней и часов имеют решающее значение для успеха кампании проекта. Как правило, основатель должен запустить проект в то время, когда потенциальные спонсоры наиболее заинтересованы в финансировании краудфандинга. Интернет-мероприятия в выходные дни обычно отличаются от рабочих в будние дни. Аналитики отмечают, что сторонники более охотно вносят свой вклад в будние дни, чем в выходные дни, причем активность увеличивается с воскресенья до пика в среду. Более того, предыдущий опыт основателя на платформе Kickstarter увеличива- ет вероятность успеха его проекта на 19,4 процентных пункта.

Следует выделить количество краудфандинговых платформ в разных странах мира представлено в табл. 1.

Отметим, что в рамках БРИКС Российская Федерация находится в одном диапазоне с Индией по количеству краудфандинговых платформ, что говорит о незначительном объеме средств, привлекаемых в краудфандинговые платформы и слабый уровень государственной поддержки и регулирования системы краудфандинга.

В аналитическом центре Statista путем наблюдений обнаружили, что в 2019 году по всему миру было проведено порядка 6455080 краудфандинговых кампаний. В целом краудфандинговые проекты имеют в среднем 47 спонсоров, что составляет менее шестой части среднего числа спонсоров для успешных кампаний. Так же было отмечено, что краудфандинговые кампании, у которых есть видео презентация проекта приносят прибыли более чем в два раза больше, чем краудфандинговые кампании, в которых нет видео [5].

Таблица 1. Количество краудфандинговых платформ в разных странах мира в 2018 гг [7]

\begin{tabular}{|c|c|c|c|}
\hline Страна & Количество платформ & Страна & Количество платформ \\
\hline Китай & 464 & Бразилия & 17 \\
\hline США & 191 & Италия & 14 \\
\hline Великобритания & 86 & Нидерланды & 12 \\
\hline Франция & 54 & Австралия & 13 \\
\hline Германия & 37 & Российская Федерация & 4 \\
\hline Канада & 34 & Индия & Южная Африка \\
\hline
\end{tabular}


Статистика краудфандинга за первое полугодие 2019 года показала, что рынок быстро растет во всех регионах мира. Тремя странами, доминирующими на мировом рынке краудфандинга, были Китай, США и Великобритания, но там, где США и Великобритания продемонстрировали впечатляющие темпы роста $-42,4 \%$ и $30,7 \%$, соответственно, объем китайского финансирования был снижен на $39,9 \%$.

Объем краудфандинговых проектов в США продолжает стремительно расти в среднем на 20\% ежегодно, составив в 2019 г. 184905 проектов (средний темп прироста $+114,53 \%$ ) [2].

Если посмотреть на весь АзиатскоТихоокеанский регион, на Китай приходится более 99\% объема. Поэтому полезно исследовать, как регион работал без Китая. Если исключить Китай из статистики, общий объем краудфандинга в Азиатско-Тихоокеанском регионе составил 6,12 миллиарда долларов, что составляет $2,0 \%$ доли мирового рынка, а в регионе наблюдались высокие ежегодные темпы роста в $69,7 \%$. Это небольшое замедление по сравнению с 2018 годом, когда годовой темп роста составил $81,5 \%$.

Страны Азиатско-Тихоокеанского региона, вошедшие в список 30 лучших в этом году:

- Китай - 1-е место с объемом краудфандинга 215,37 млрд.

- Австралия - седьмое место с объемом краудфандинга 1,17 млрд. долларов.

- Япония - 8-е место с объемом краудфандинга 1,07 млрд. долларов.

- Южная Корея - 11-е место с объемом краудфандинга 753,4 млн. долларов.

- Сингапур - 16-е место с объемом краудфандинга 499,7 млн. долларов.

- Новая Зеландия - 22-е место с объемом краудфандинга 276,2 млн. долларов [3].

Франция в ЕС является одной из лидирующих стран по созданию краудфандинговых платформ. Она занимает третье место в мире по их количеству и первое - в Европе по объемам аккумулированных средств, во много благодаря существенной поддержке краудфандинга со стороны правительства, общества и общественности. Здесь по состоянию на март 2020 года на платформе Kisskissbankbank размещено 37992 проекта, в том числе профинансированных - 21713 проектов. Наиболее популярными проектами краудфандинга, зарегистрированными на платформе являются музыкальные проекты (на их долю приходится 14,41\%), проекты в области художественной фотографии (13,04\%), проекты в сфере благотворительности (11,56\%). Менее популярными выступают проекты в сфере комиксов $(0,45 \%)$, ремесла $(1,91 \%)$ сельского хозяйства $(1,71 \%)$.

В перспективе можно ожидать «объединение банков и краудфандинговых платформ, ведь реальная экономика получит стимул, если банковская и альтернативная финансовая индустрия будут делать следующие шаги в сочетании новых и традиционных финансовых инструментов» [8].

Значительная часть компаний, задействованных в краудфандинговой индустрии, осуществляет деятельность исключительно онлайн, создавая удобные для потребителей платформы. Для сравнения, традиционным финансовым фирмам приходится постоянно ремоделировать собственную продукцию и процессы, чтобы соответствовать изменчивым потребительским запросам [6].

В настоящее время в России принят федеральный законодательный по краудфандингу, который:

- определяет регулируемую услугу;

- устанавливает требования к инвестиционной платформе, ее оператору и участникам;

- описывает процесс инвестирования посредством инвестиционной платформы, в том числе особенности инвестирования денежных средств в эмиссионные ценные бумаги, размещаемые с использованием инвестиционной платформы;

- устанавливает требования к раскрытию и предоставлению информации [1].

Законом предусмотрены меры снижения рисков и следующие элементы защиты инвесторов:

- объем инвестиций, собираемых одним привлекающим лицом в течении года, не может превышать 1 млрд. руб. (за исключением инвестиций, привлекаемых публичными акционерными обществами путем продажи токенов;

- объем инвестиций, предоставляемых одним инвестором в течении года,- не более 600 тыс. руб.;

- установление минимальных требований к привлекающим лицам;

- установление минимальных требований к оператору цифровой платформы;

- право инвесторов отозвать свое заявление в отношении инвестиционного предложения в течении пяти рабочих дней; 
- предоставление инвесторам информации о привлекающем лице;

- предоставление инвесторам информации об инвестиционном предложении [1].

Анализ показывает, что трансформация западного краудфандинга в нынешних формах произошла до кризиса 2008 года, а в России только в 2013 году. В нашей стране краудфандинг не так популярен в России, как это допустимо в США или Китай. Одной из причин является недостаточный уровень доверия к новым финансовым инструментам, к каковым относится и краудфандинг. Когда гражданину России, физическому или юридическому лицу предлагается инвестировать свои деньги на безвозмездной основе в любой бизнес, о котором они впервые слышат, то люди думают о мошенничестве, так как этот вид финансирования является новым для России. Следует отметить рост интереса к краудфандингу. Сейчас 70\% специалистов знают об этом явлении, однако они пока спонсируют не так активно, как креативные личности, которые подают идеи.

Выводы. Показано, что основными проблемами развития краудфандинга в России являются: финансирование преимущественно, социальных проектов; незначительный объем средств, привлекаемых с помощью краудфандинговых платформ в России; слабый уровень государственной поддержки краудфандинга; недостаточный уровень государственного регулирования (не закрытые пробелы в законодательстве); недостаточный уровень доходов населения и, как следствие, ограниченный платежеспособный спрос на финансирование проектов; отсутствие культуры коллективных частных инвестиций; неразвитость краудфандинговой инфраструктуры.

Целью государственного регулирования систем краудфандинга является обеспечение разработки эффективного государственного регулирования и создания благоприятных условий для краудфандинговой деятельности, а именно: создание и повышение эффективности деятельности краудфандинговых платформ, легализация доходов авторов краудфандинговых проектов, мотивирование индивидуумов к участию в краудфандинговых проектах и т.п.

Проведенный анализ функционирования российского рынка краудфандинга дает возможность выделить следующие специфические его особенности:
- финансируются, как правило, социальные проекты в области здравоохранения, культуры, образования и т.д.;

- общие объемы средств, которые привлечены с помощью краудфандинговых платформ в России, являются незначительными;

- предпринимательские технологические проекты востребованы, однако не находят нужного уровня поддержки, поэтому российские технологические стартапы финансируются на зарубежных краудфандинговых платформах;

- недостаточный уровень государственного регулирования (пробелы в законодательстве);

- недостаточный уровень доходов населения и, как следствие, ограниченный платежеспособный спрос на финансирование проектов;

- низкий уровень знаний в сфере краудфандинга; наличие недоверия к данному способу финансирования среди населения;

- неразвитость краудфандинговой инфраструктуры.

Анализ тенденций функционирования краудфандинга в экономически развитых странах и его специфических российских особенностей позволяет предложить следующие научнопрактические рекомендации по эффективному функционированию и дальнейшему его развитию в российских условиях:

1. Совершенствование законодательства и соответствующего правового поля в сфере краудфинансирования.

2. Разработка «дорожной карты» осуществления краудфинансирования, в которой будет предусмотрено внедрение комплекса мер, осуществив которые можно создать систему, которая регулирует рынок.

3. Стимулирование прихода на рынок различных типов частных инвесторов путем прозрачности сбора средств и удобства самого перевода; развитой коммуникации между разработчиками проектов и инвесторами.

4. Создание механизмов минимизации рисков для непрофессиональных инвесторов путем диверсификации объема инвестиций.

5. Развитие краудфандинговой инфраструктуры на основе формирования различных видов краудплатформ.

6. Формирование культуры коллективного финансирования на основе информационного обеспечения, осведомленности широких слоев населения с целью создания положительного имиджа краудфандинга. 
Решение выявленных проблем и внедрение предложенных рекомендаций будет способствовать развитию краудфандинговой деятельности в стране. Необходимо создавать новые краудфандинговые платформы, в первую очередь на базе университетов и институтов, которые сформируют определенный импульс по поддержке инновационных проектов и методам оценки их результативности.

\section{Библиографический список}

1. Федеральный закон от 2 августа 2019 г. № 259-Ф3 () «О привлечении инвестиций с использованием инвестиционных платформ и о внесении изменений в отдельные законодательные акты Российской Федерации»

2. Научная электронная библиотека Elibrary [Электронный ресурс] Режим доступа: https:/elibrary.ru/item. asp?id $=42631798$ \& (дата обращения: 28.11 .2020 )

3. Статистическая электронная база P2PMarketData 2020 [Электронный ресурс] Режим доступа: https:// p2pmarketdata.com/crowdfunding-statistics-worldwide/ (дата обращения: 24.11.2020)

4. Статистическая электронная база P2PMarketData 2020 [Электронный ресурс] Режим доступа: https:// financeparticipative.org/etude-sur-le-financement-participatif-comme-outil-pour-la-relance/ (дата обращения: 24.11.2020)

5. Статистическая электронная база Statista.com 2020 [Электронный ресурс] Режим доступа: https://www. statista.com/topics/1283/crowdfunding/ (дата обращения: 24.11.2020)

6. Чепкова T. Британский регулятор взялся за краудфандинг. [Электроный ресурс] Режим доступа: https:// ru.forexmagnates.com/britanskiy-regulyator-vzyalsya-za-kraudfanding (дата обращения: 24.11.2020)

7. Crowdfunding's Potential for the Developing World. // Washington: World Bank, 2013. - 103 p. (p.20) // Каким краудфандинговым площадкам можно доверять в России? [Электронный ресурс] Режим доступа: https:// svoedelo-kak.ru/finansy/kraudfanding.html (дата обращения: 24.11.2020)

8. The Netherlands a Crowdfunding Leader in Europe 2017. Holland trade and invest. [Электронный ресурс] Режим доступа: https://www.hollandtradeandinvest.com/latest/news/2016/april/05/the-netherlands-crowdfundingleader-in-europe (дата обращения: 24.11.2020) 